EPJ Web of Conferences 59, 12002 (2013)

DOI: $10.1051 /$ epjconf/20135912002

(C) Owned by the authors, published by EDP Sciences, 2013

\title{
Recent progress of fuel layering study for FIREX cryogenic target
}

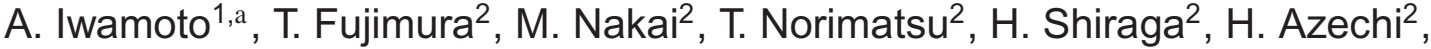 \\ Y. Fujimoto ${ }^{2}$, S. Machi ${ }^{2}$ and H. Sakagami ${ }^{1}$ \\ ${ }^{1}$ National Institute for Fusion Science, Toki, Gifu 509-5292, Japan \\ ${ }^{2}$ Institute of Laser Engineering, Osaka University, Suita, Osaka 565-0871, Japan
}

\begin{abstract}
The collaboration research of ILE and NIFS has made progress on the FIREX target developments. We have two fuel layering strategies: a foam shell method and a conical laser guide heating technique. To date, preliminary and principle demonstration stages on both fuel layering methods have been reached. This paper describes the present status of the target developments.
\end{abstract}

\section{INTRODUCTION}

In several years, a cryogenic target will be applied for final integrated experiments of the first phase of the Fast Ignition Realization EXperiment (FIREX). The National Institute for Fusion Science (NIFS) has collaborated with the Institute of Laser Engineering (ILE), Osaka University to develop its cryogenic target. ILE is in charge of the target fabrication, and NIFS has a responsibility for cryogenic technologies. We have two fuel layering strategies: a foam shell method $[1,2]$ and a conical laser guide heating technique [3]. Foam and Polystyrene (PS) shells with $500 \mu \mathrm{m}$ in diameter were fabricated successfully and were assembled with a conical laser guide and a fill tube into a FIREX target. They have been supplied to cryogenic experiments. Dedicated apparatus has been used for fuel layering demonstrations in these targets [4]. This paper describes recent progress of the fuel layering study on both strategies.

\section{SHELL AND TARGET FABRICATIONS}

ILE has produced $500 \mu \mathrm{m}$ PS and foam shells. A PS shell has already met the specification for non cryogenic FIREX experiments. Its required specification is $500 \mu \mathrm{m}$ in diameter with $7 \mu \mathrm{m}$ in thickness. The same shell is used for cryogenic fuel layering experiments. The foam shell is still under development and several prototype $\sim 500 \mu \mathrm{m}$ shells with $\sim 20 \mu \mathrm{m}$ foam layer thickness were fabricated. A resorcinol/formalin (RF) material was utilized to create a $500 \mu \mathrm{m}$ foam shell [5]. Machining of the shells to make a hole for a conical laser guide and full tube insertion has been stable [6]. All parts were glued together by epoxy resin; however its fillet was not uniform because of handworked gluing. Its gas leak tightness was confirmed at room temperature [7]. Figures 1(a) and (b) show the assembled FIREX targets. The represented foam shell has $521 \mu \mathrm{m}$ in diameter, $18 \mu \mathrm{m}$ of foam layer thickness and $90 \mathrm{mg} / \mathrm{cm}^{3}$ density.

\footnotetext{
ae-mail: iwamoto.akifumi@LHD.nifs.ac.jp
}

This is an Open Access article distributed under the terms of the Creative Commons Attribution License 2.0, which permits unrestricted use, distribution, and reproduction in any medium, provided the original work is properly cited. 

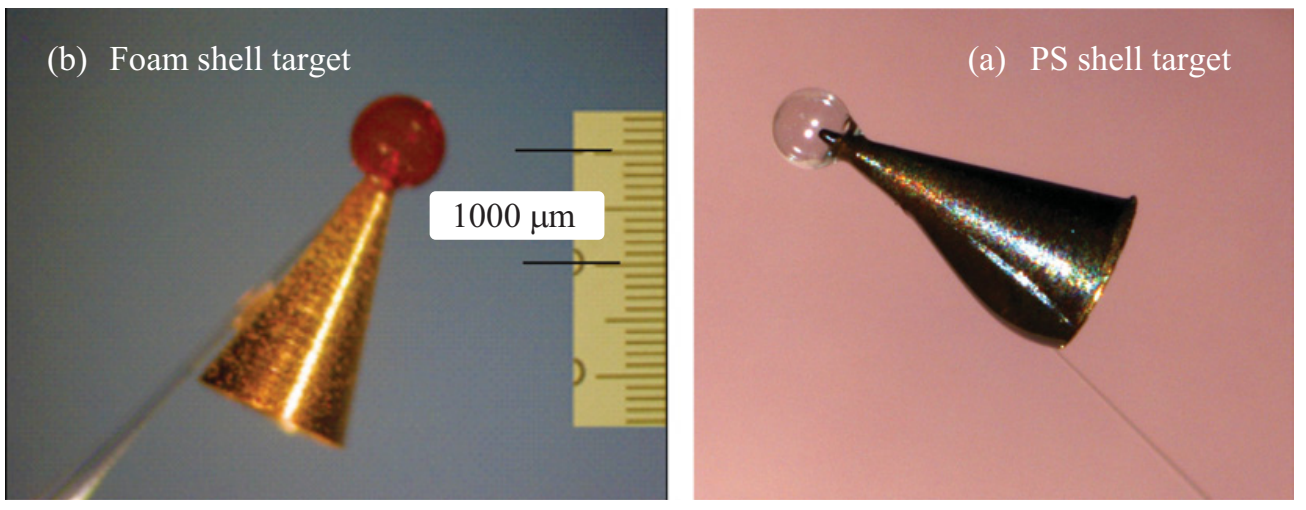

Figure 1. (a) Fabricated foam and (b) PS shell targets.

For solid fuel layering, the cryogenic robustness of the target must be guaranteed. Several cooling down tests for $500 \mu \mathrm{m}$ shell targets have been conducted to date; however no $500 \mu \mathrm{m}$ shell target could survive during cooling down process. According to a previous study on this problem [8], different thermal contractions among the materials resulted in shell breakup. To confirm the influence of their thermal contractions, a parylene conical laser guide whose thermal contraction coefficient is close to that of PS was tried out to assemble a FIREX target. The target could keep its gas leak tightness at cryogenic environment. The material selection for a conical laser guide is going to be negotiated with the plasma physics side.

\section{DEMONSTRATION OF CONE GUIDE HEATING TECHNIQUE}

The cone guide heating technique has been developed using a prototype target with a 2 mm diameter PS shell. Its detail was already reported. See reference [3] for a full account of the layering demonstration. The target configuration is the same as a typical FIREX target except for the shell diameter and thickness. Normal- $\mathrm{H}_{2}\left(\mathrm{n}-\mathrm{H}_{2}\right)$ was used as a surrogate fuel for the layering demonstration. A brief explanation of the technique is as follows. Liquefied $n-\mathrm{H}_{2}$ was supplied around a conical laser guide utilizing the effect of surface tension, and then it was solidified. Irradiation of a low power laser beam to the conical laser guide heated it up and resulted in the redistribution of the solid $\mathrm{H}_{2}$ from the perimeter of the conical laser guide to the whole shell interior. It means that no solid $\mathrm{H}_{2}$ layer existed just around the conical laser guide at this point. After that, ramping up and down of the temperature between over and below the $\mathrm{H}_{2}$ triple point allowed refilling liquid $\mathrm{H}_{2}\left(\mathrm{LH}_{2}\right)$ around the conical laser guide again. At the same time, a lump of the solid $\mathrm{H}_{2}$ could survive during the process because of its latent heat and heat capacity. Several cycles of fuel refilling were needed to accumulate a desired solid $\mathrm{H}_{2}$ layer thickness. Consequently, a $155 \sim 192 \mu \mathrm{m}$ thickness layer was successfully formed. Modification of this technique has been studied to meet required specifications. This technique is going to be applied to a $500 \mu \mathrm{m}$ PS shell target.

\section{FOAM SHELL METHOD}

\subsection{Principle demonstration for low void fraction realization using a triangular prism shaped sample}

To complete fuel layering into a foam shell, preventing residual voids in the solid fuel filled within each cell of foam material is an important issue [9]. The voids could come from the density gap in a liquid-solid transition. We are going to apply the effect of capillary attraction in a liquid state to avoid 

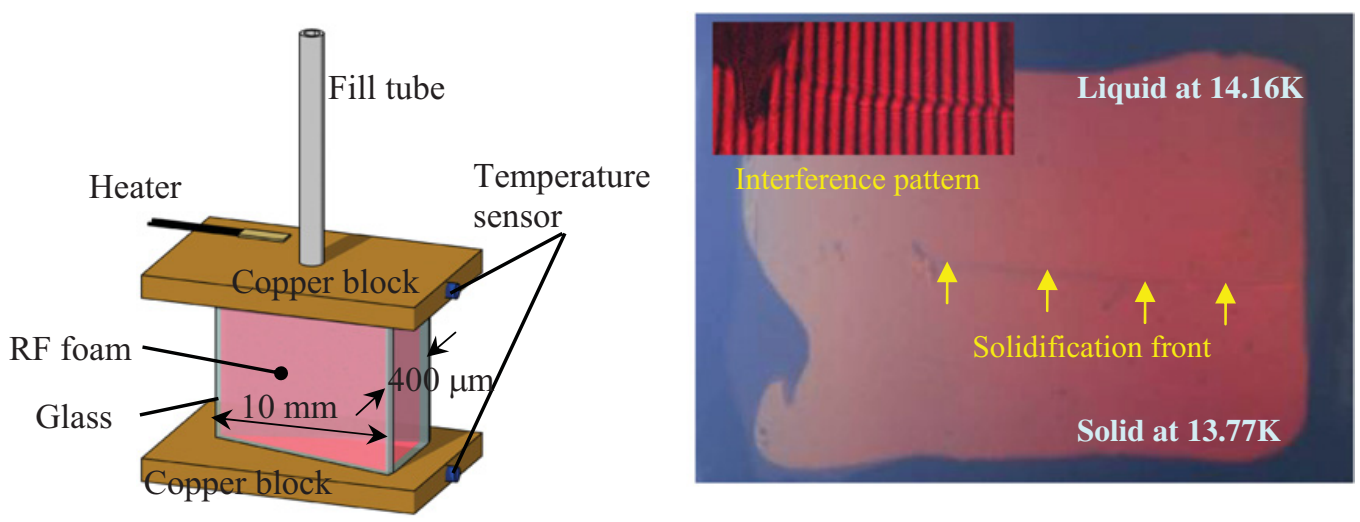

Figure 2. (a) Schematic of the sample, (b) moving solidification front demonstration and its interference pattern.

them. Continuous supply of $\mathrm{LH}_{2}$ to the solidification front would be realized by this effect and would reduce the formation of residual voids. How to realize the controlled solidification front is the key issue of this idea. To date, the basic study to demonstrate this idea has been conducted. Figure 2 (a) shows the sample configuration. We chose a triangular prism shape of a foam material for easy observation by an interferometer. The foam layer was molded among glass plates, and they were sandwiched between copper plates with cernox sensors. All parts were glued by epoxy resin. It was put in the dedicated apparatus and was cooled by ambient gaseous $\mathrm{He}(\mathrm{GHe})$. After filling $\mathrm{LH}_{2}$ within the foam material through the fill tube, the temperature difference of $\sim 400 \mathrm{mK}$ between the top and bottom was generated by heating the upper copper block. Then, the sample temperature was lowered gradually less than the $\mathrm{H}_{2}$ triple point. Solidification was started from the bottom, and the front was moved upward (see Figure 2(b)). This method could control the direction of the moving solidification front. The density gap could be observed clearly at the front by an interferometer. It means that the continuous supply of $\mathrm{LH}_{2}$ to the solidification front and the reduction of residual voids were succeeded. In a brief estimation, a reduced void fraction was confirmed. The detail of this study will be published to a different paper.

\subsection{Simulation of the proposed layering sequence for the FIREX target}

To apply the demonstrated method mentioned above to the FIREX target, shell temperature control is essential. Conical laser guide heating is one possibility to generate the required temperature gradient along a shell's foam layer. The irradiation of a low power laser beam might be applied for it. The ANSYS code (ANSYS, inc) is used to simulate the shell temperature control. An axisymmetric model of the FIREX target is shown in Figure 3(a). To simplify the model, the fill tube is ignored. The shell and conical laser guide are cooled by different heat transfer coefficients to ambient GHe. Considering the $\mathrm{H}_{2}$ latent heat makes it possible to simulate a liquid-solid transition. An assumed process to realize the solidification front control is as follows. Initially, the foam layer is filled with $\mathrm{LH}_{2}$; ambient GHe temperature is $14.0 \mathrm{~K}$ and is monotonically lowered to $10.0 \mathrm{~K}$ in $10000 \mathrm{sec}$. A uniform heat input to the conical laser guide is assumed to be $6.6 \times 10^{-5} \mathrm{~W}$.

The solidification front control was successful. $\mathrm{H}_{2}$ solidification arose from the bottom when the ambient GHe temperature was $10.4 \mathrm{~K}$. Then the transition front moved toward the conical laser guide. Figure 3(b) represents the temperature distribution in the foam shell after $8140 \mathrm{sec}$. It took $\sim 270 \mathrm{sec}$ to complete the solidification of whole $\mathrm{LH}_{2}$. This would be slow enough to supply $\mathrm{LH}_{2}$ continuously to the solidification front by the effect of capillary attraction. Judging from this simulation, our proposed method to realize a low void fraction is applicable to the FIREX target configuration. 


\section{EPJ Web of Conferences}
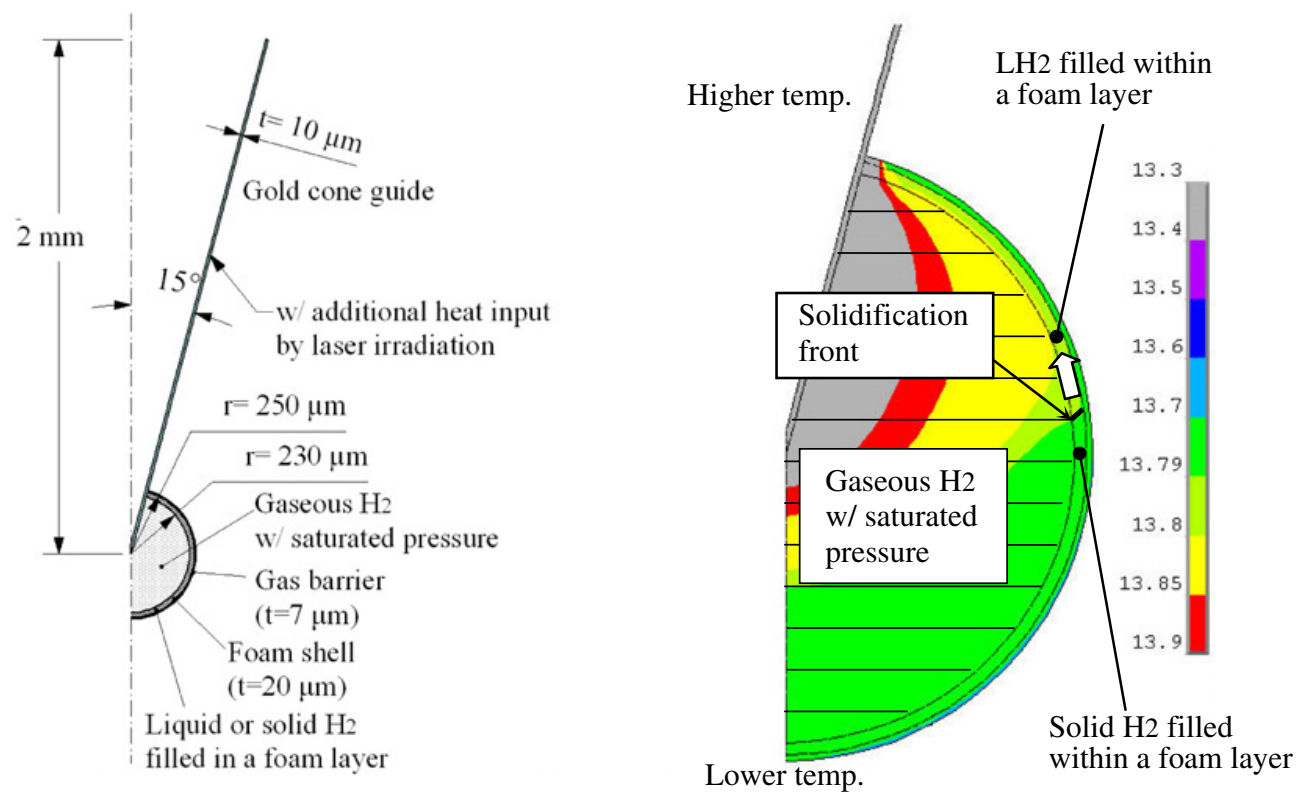

Figure 3. (a) Model for foam shell temperature control, (b) simulation of moving solidification front in a foam shell.

\section{SUMMARY}

The collaboration research of ILE and NIFS has made progress on the FIREX target developments. Two strategies: the foam shell method and the conical laser guide heating technique are applied to realize the FIREX cryogenic target. The $500 \mu \mathrm{m}$ PS and foam shell fabrications are almost stable. Assembled FIREX targets with both shells are available for cryogenic experiments. Preliminary and principle demonstrations on fuel layering in both strategies have been finished.

\section{References}

[1] R. A. Sacks, D. H. Darling, Nucl. Fusion 27, 447(1987)

[2] K. Nagai, H. Azechi, F. Ito, A. Iwamoto, Y. Izawa, T. Johzaki, et al., Nucl. Fusion 45, 1277 (2005)

[3] A. Iwamoto, T. Fujimura, M. Nakai, K. Nagai, T. Norimatsu, H. Azechi, et al., J. Phys.: Conf. Ser. 244, 032039 (2010)

[4] A. Iwamoto, R. Maekawa, T. Mito, M. Okamoto, O. Motojima, S. Sugito, et al., Fusion Eng. Des. 81, 1647 (2006)

[5] F. Ito, K. Nagai, M. Nakai, T. Norimatsu, A. Nikitenko, S. Tolokonnikov, et al., Jpn. J. Appl. Phys. 45, L335 (2006)

[6] T. Fujimura, M. Nakai, A. Iwamoto, H. Hayashi, M. Tanabe, Y, Izawa, et al., J. Phys.: Conf. Ser. 244, 032037 (2010)

[7] T. Fujimura, M. Nakai, A. Iwamoto, K. Nagai, H. Homma, K. Tanabe, et al., Plasma Fusion Res. 4, S1010 (2009)

[8] A. Iwamoto, T. Fujimura, A. Sunahara, H. Sakagami, T. Norimatsu, et al., Plasma Fusion Res. 6, 2404070 (2011)

[9] J. K. Hoffer, J, D. Sheliak, D. A. Geller, D. Schroen, P. S. Ebey, Fusion Sci. Technol. 50, 15 (2006) 